\title{
O DIREITO E SUA LINGUAGEM: AS CONTRIBUIÇÕES DA SEMÂNTICA PARA UMA ANÁLISE CRÍTICA DO MODELO DE REGRAS JURÍDICAS
}

\author{
Augusto Carlos de Menezes Beber ${ }^{1}$ \\ Caroline Müller Bitencourt ${ }^{2}$
}

\begin{abstract}
RESUMO
Na busca por objetividade e segurança jurídica, encontra-se em Hart, dito positivista, valorosos estudos sobre o Direito e, em especial, sobre seus elementos estruturais, como as regras jurídicas. Entretanto, em Hart pode-se perceber que, mesmo face às especificidades das regras, ainda nelas existe uma chamada textura aberta, propícia à interpretação. Neste sentido, buscam-se as raízes dos problemas de aplicação das regras, por meio de um estudo encontrado em Warat sobre a linguagem associada ao Direito. Sendo a linguagem escrita o veículo de transmissão das regras, percebe-se, desde logo, que os limites impostos à linguagem também se estenderão à aplicação das regras jurídicas. Discute-se, desta forma, os conflitos existentes em Direito através da semiótica, especialmente por meio da semântica, no que tange a relação do significado dos signos jurídicos com o objeto que designam. Neste panorama, fez-se também uma análise exemplificativa da ADI 4.277, que versa sobre a união estável homoafetiva, na qual evidencia-se uma questão linguística como cerne da questão jurídica. Para tal tarefa utilizou-se o método hermenêutico e, como técnica de pesquisa, a bibliográfica.
\end{abstract}

Palavras-chave: Positivismo. Regras jurídicas. Semântica. Aplicação. Linguagem.

\begin{abstract}
In the search for objectivity and legal security, it is found in Hart, known as a positivist, valuable studies of Law, in particular, about its structural elements, as the legal rules. However, in Hart, it is noticed that, even the specific characteristics of the rules, there is a socalled open texture, where there is room for interpretation. In this sense, this paper seeks the roots of the problems of enforcement through a study found in Warat about the language associated with the right. Considering the written word as the vehicle of transmission of rules, it is noticed, first, that the limits of language are also extended to the application of legal rules. It is argued, in this way, the conflicts in law through semiotics, especially the semantics regarding the relationship between the significance of the juridical signs and the object that they designate. In this scene, it was also made an exemplified analysis of the ADI 4277, which deals with the stable homo-affective union and in which clearly was a language-related issue in the center of the legal problem. It was used, for this paper, the hermeneutic method and, as a research tool, it was used the bibliographic technique.
\end{abstract}

Keywords: Positivism. Legal rules. Semantics. Application. Language.

\footnotetext{
${ }^{1}$ Aluno do Curso de Direito da Universidade de Santa Cruz do Sul - UNISC. <augusto_beber@yahoo.com.br>

2 Doutora em Direito. Docente do Curso de Graduação e Programa de Pós-Graduação em Direito da Universidade de Santa Cruz do Sul - UNISC. <caroline.mb@terra.com.br>
} 


\section{INTRODUÇÃO}

O presente trabalho tem por objetivo investigar o Direito, por meio da matriz positivista de Hart, a fim de observar o fenômeno da aplicação das regras jurídicas. Trata-se de uma pesquisa de caráter bibliográfico, realizada a partir do método hermenêutico, com o objetivo de identificar as limitações do modelo de aplicação das regras segundo as próprias limitações da linguagem encontradas nos ensinamentos de Warat.

Tal jornada se justifica pela oportunidade de identificar os problemas de aplicação das regras, a fim de que se possa lançar luz sobre alguns aspectos neste campo, que é envolvido por mitos e teorias. No cenário brasileiro, percebe-se que, com os holofotes voltados para o judiciário, as decisões tomadas pelo Supremo Tribunal Federal têm gerado um debate cada vez maior sobre os métodos empregados na interpretação e aplicação das regras jurídicas. Neste sentido, busca-se questionar o papel da textura aberta da linguagem presente nas regras jurídicas para que se possa entender o papel do intérprete na construção das premissas, para se chegar a um resultado final.

Propõe-se a investigar, dessa maneira, se as regras jurídicas, vistas como um paraíso na produção de interpretações objetivas, vêm de fato exercer este papel (um tanto utópico) quando se encontram complexas situações em Direito. A grande problemática aqui encontrada em relação à aplicabilidade das regras indica uma questão semântica, na qual se questiona o significado dos termos contidos dentro das regras jurídicas. Neste momento, o foco epistêmico desloca-se para o estudo da linguagem, com o auxílio de Warat (1995), para investigar os fenômenos que ocorrem e encontrar o significado de um signo na resolução do conflito no mundo jurídico. De forma ilustrativa, traz-se a decisão proferida pelo Supremo Tribunal Federal na ADI 4.277, de forma a casar os pressupostos trabalhados com a realidade jurídica brasileira.

Assim, espera-se refletir sobre a tentativa positivista de estabelecer um critério de juridicidade distante da moral e da política, analisando a obra de Hart, expoente do positivismo jurídico contemporâneo. Levam-se as expectativas criadas pela teoria de Hart até os questionamentos de Posner, para então encontrar as incertezas produzidas pelas regras jurídicas no diagnóstico produzido em Warat. 


\section{O LOCAL DAS REGRAS NO ORDENAMENTO JURÍdICO SEGUNDO O POSITIVISMO HARTIANO}

Em Hart, especialmente na sua obra mestra, O Conceito de Direito (2001), encontrase a crítica ao modelo jurídico criado por Austin referente à ideia de comandos ou ordens emitidas pelo soberano, ao tempo em que contém uma proposta de compreensão do Direito através da relação entre regras primárias e secundárias, analisadas por meio de seu aspecto interno e externo.

O trabalho de Hart apresenta características clássicas do positivismo jurídico, encontradas também em jusfilósofos como Kelsen e Ross. Hart se insere dentro do positivismo, pois, em linhas gerais, busca delimitar o universo jurídico a ponto de evitar os reflexos controvertidos produzidos pela ética ou pela política. Na compreensão do positivismo jurídico, portanto, encontra-se a compreensão do próprio pensamento de Hart. O positivismo, conforme ressalta Barzotto (2007), nasceu acompanhado de um ideal de segurança. O homem, ansioso por livrar-se dos grilhões do Estado Absolutista, clamava a existência de uma ordem que garantisse a segurança do indivíduo ante os caprichos do próprio Estado, presentado pelo monarca de poderes ilimitados. Neste momento, o positivismo foi hasteado como a grande bandeira que representaria a desejada segurança que viria com o Estado Liberal.

O positivismo buscaria, portanto, caracterizar o Direito através de um sistema normativo, que, para Scarpelli (1965), citado por Barzotto (2007, p. 19), implica na "presença de critérios regulativos em relação aos quais se pode decidir face a qualquer norma se pertence ou não ao sistema." Este critério de juridicidade, para o positivismo, é a validade, em contraposição àqueles critérios adotados por correntes como o jusnaturalismo e o realismo. Para o positivismo, norma jurídica é norma válida, considerando-se que a validade será determinada pelo próprio ordenamento jurídico. Dessa forma, pensa-se num sistema autoprodutivo, o qual se compõe de uma norma suprema e não de um poder supremo. Para Bobbio (1992, apud BARZOTTO, 2007),

\footnotetext{
Um ordenamento jurídico é um sistema normativo no qual a produção de normas do sistema é ela mesma regulada por outras normas do sistema em um processo que remontando da norma inferior à norma superior alcança necessariamente (onde, contudo, a necessidade deve ser entendida como necessidade lógica e não factual) a norma fundamental, que do ponto de vista de um positivismo rígido e rigoroso é o único fundamento possível do direito: o único fundamento possível de um ordenamento que regulando a própria produção se autoproduz (p. 21, grifo do original).
} 
Então, extrai-se que o positivismo, por meio da fala de Barzotto (2007), além da segurança, procura produzir um conceito autônomo do Direito. Neste contexto, encontra-se Hart (2001), que, como o próprio nome de sua obra-mestra prenuncia, busca encontrar um conceito para o Direito. Em seus questionamentos prévios, depara-se inevitavelmente com a própria definição de regra. Assim, da mesma forma como o fez com Direito, percebe que a complexidade desses elementos faz com que o analista consiga apenas identificar espécies destes, mas não encontrar uma definição exata para eles. Nesta jornada, percebe a fusão parcial que existe entre as ideias de Direito, regras e sistema jurídico, ao ponto de tornar-se inviável questionar o conceito daquele sem questionar o próprio conceito de regra. Tal é o ponto de partida da investigação do autor, que circunscreve alguns aspectos que compõem uma regra a partir da desconstrução do pensamento austiniano.

Como de fato Hart (2001) comenta, existem regras de múltiplos tipos ao lado das regras jurídicas, como as regras de linguagem, as de jogos ou as regras de etiqueta. Neste meio, o primeiro desafio que encontra é saber diferenciar uma regra de um hábito geral convergente. Começa investigando, portanto, a origem das regras e como estas se relacionam com os sujeitos que envolvem. Estabelece, num primeiro momento, que elas podem surgir de diversas formas e que se relacionam de modo flexível, conforme o padrão de comportamento que regulam. Tratando-se de Direito, por exemplo, vislumbra-se que as regras podem surgir a partir de atos legislativos e possuir tanto um caráter imperativo quanto um caráter facultativo.

Hart (2001), neste ponto, critica a doutrina vigente em sua época, elaborada por Austin, que via o Direito por meio de ordens baseadas em ameaças ou comandos do soberano. Trata essa doutrina como incompleta ou insuficiente; no âmbito do Direito, admite que tal explicação consegue ser aplicada quando se fala de leis penais que preveem uma sanção para determinada conduta. A construção falha, contudo, conforme o autor explica, quando se fala em regras que facultam ao sujeito determinada ação ou ao falar-se em regras que instruem o sujeito quanto a procedimentos que este deve seguir para alcançar determinado desejo.

Para fundamentar sua posição, Hart (2001) faz uma análise da estrutura da regra em seu aspecto interno e externo e, com isso, consegue também diferenciá-la de meros hábitos e condutas gerais convergentes. Explica que, do ponto de vista externo, um observador pode verificar a continuidade de determinada ação tomada por alguns sujeitos e, da mesma forma, perceber que há uma punição ou reprovação para aquele que cometer um desvio do comportamento esperado. Tal situação não configuraria, por si só, uma regra. Levando-se em consideração, contudo, o aspecto interno da conduta, verifica-se um novo quadro. A regra se constitui quando, além do observado aspecto externo, o sujeito exerce uma atitude crítica 
reflexiva quanto ao comportamento exercido; o sujeito o encara como um padrão a ser seguido por todos.

O que não se refuta, portanto, na teoria hartiana do Direito, é o papel desempenhado pelas regras na formação de um sistema jurídico. Afirmar que um sistema jurídico consiste, de modo geral, em regras, segundo Hart (2001), não suscita demasiadas dificuldades de compreensão ou aceitação. A crítica está concentrada, portanto, para ele, na mencionada concepção da natureza das regras, assim como na sua relação com a moral e com a justiça.

Da mesma forma, parece haver um consenso teórico sobre a alegação de que as regras se relacionam com condutas e que a comunicação destas através de formas explícitas de linguagem parece transmitir clareza, segurança e certeza - o ideal formalista de uma regra jurídica (ainda que insidioso, como será visto mais adiante). Neste sentido, em Posner (2007), jurista norte-americano, encontram-se críticas às aparentes vantagens da utilização de regras simples num determinado sistema jurídico, principalmente no que se refere à redução da discricionariedade oficial e à redução da incerteza relativa aos direitos e deveres jurídicos.

Em referência à comunicação dos padrões gerais de conduta, mesmo quando estes forem veiculados por formas gerais explícitas de linguagem, ainda assim podem dar ensejo a dúvidas no momento da aplicação em determinados casos particulares. Nestas situações, Hart (2001) ressalta que nem os cânones da interpretação podem eliminar a incerteza, por estes também serem regras gerais sobre o uso da linguagem. Dessa forma, observa que

Os casos simples, em que os termos gerais parecem não necessitar de interpretação e em que o reconhecimento dos casos de aplicação parece não ser problemático ou ser "automático" são apenas os casos familiares que estão constantemente a surgir em contextos similares, em que há acordo geral nas decisões quanto à aplicabilidade dos termos classificatórios (p. 139).

Assim, Hart (2001) reconhece que há certas limitações quanto ao uso da linguagem, quando dela se faz uso para a transmissão de padrões de conduta por regras gerais. Da mesma maneira, destaca que, a dependência das linguagens naturais com sua textura aberta torna-se um indicativo de que não se deve acarinhar, mesmo de forma ideal, uma regra tão específica ou detalhada que torne a sua incidência sempre antecipadamente resolvida. Há uma necessidade de escolha e tal ocorre devido à própria condição humana. Hart parte da ideia de que poderiam ser produzidas regras fechadas num mundo caracterizado por um número finito de aspectos, no qual tudo poderia ser conhecido de forma a ser possível antecipar cada possibilidade. Tal mundo não pertence aos homens, como expõe, pois não há como estes tomarem conhecimento de todas as situações que o futuro vem a trazer. A linguagem geral da 
regra dita, neste contexto, as condições que qualquer coisa deve satisfazer para se encontrar em sua zona de aplicação. Faz-se uma escolha para que a finalidade inicial de uma regra se torne mais determinada e se resolva a questão referente ao seu sentido.

Em relação à linguagem, Posner (2007) destaca que esta se assemelha ao Direito no sentido de que suas regras também são mutáveis, inclusive no seu uso. Assim como acrescenta, ambos se situam, de certo modo, além do certo e do errado. Exemplificando, o autor mostra expressões que, mal empregadas no passado, por meio do costume, somaram-se ao vocabulário oficial e, hoje, não são mais passíveis de correção. Dessa forma, preconiza que, "tendo em vista que o direito, assim como a linguagem, valoriza a estabilidade, os erros jurídicos também podem ser sancionados pelo tempo e pelo uso" (POSNER, 2007, p. 70).

MacCormick (2007), num estudo sobre a obra de Hart, avalia a teoria apresentada por este como um sistema jurídico visto como um sistema de regras sociais, as quais derivam de fontes sociais e existem em razão de práticas desta mesma natureza. Desta forma, observa que o positivismo jurídico de Hart se choca com a indeterminação relativa das regras sociais e, por consequência, também das regras jurídicas.

Para Hart (2001), o conceito de direito existe como uma união de regras primárias e secundárias. Em MacCormick (2007), tem-se que as regras primárias firmam as obrigações e os deveres dos sujeitos. Por outro lado, as regras secundárias não possuem esta mesma característica, de maneira que não prescrevem formas de conduta obrigatórias, mas se relacionam com as regras primárias de diversos modos. MacCormick expõe estar nesta relação, entre regras primárias e secundárias, a qualidade sistemática do Direito. Há regras, como explica, que conferem poderes para certas pessoas proferirem sentenças em casos de transgressões das regras primárias, impondo punições aos infratores. Tais regras, que conferem competência aos agentes, não são prescritivas de deveres como as regras primárias, mas sim adjudicam poderes de julgamento e execução de lei. Estas regras, como MacCormick esclarece, são chamadas por Hart (2001) de regras secundárias de julgamento. Ao lado dessas, destaca o que Hart trouxe como regras secundárias de alteração. Estas, por sua vez, vêm a conferir poderes para alterar a legislação existente, de forma a emendar, revogar ou decretar novas regras, seja por um legislador do poder público, seja por uma decisão judicial ou costume social. Por fim, para fechar o rol das regras secundárias, MacCormick traz a regra de reconhecimento, criada por Hart (2001) para determinar a validade de todas as regras de um sistema jurídico. O sistema parte, em Hart segundo MacCormick (2007), desta regra a partir do momento que todas as regras, sejam elas de julgamento e alteração, ou de obrigação e 
deveres, são válidas somente conforme os critérios de validade contidos na regra de reconhecimento.

Dessa forma, MacCormick (2007) apresenta Hart como um positivista jurídico, devido ao que considera uma insistência, na teoria hartiana, na dissociação conceitual entre o Direito e a Moral. "Os positivistas negam que o Direito como tal seja essencialmente moral, e afirmam que a existência de uma lei é sempre uma questão conceitualmente distinta daquela do mérito ou demérito moral desta" (MACCORMICK, 2007, p. 40). Para Posner (2012), Hart se encaixa numa versão forte do positivismo ao tornar condição necessária para ser revestida com o pano jurídico a identificação de uma regra primária de obrigação pela regra de reconhecimento do sistema. Dessa maneira, Hart (2001) estabelece o critério de juridicidade dentro do próprio ordenamento jurídico, vinculando-se à escola positivista. Lembrando-se das lições trazidas por Barzotto (2007), citadas anteriormente, conclui-se que, numa reflexão sobre as regras dentro do positivismo de Hart, estas, quando o direito é isolado da moral e da política, só serão jurídicas se atenderem aos pressupostos do critério último de identificação do direito, que, para o autor, é a regra de reconhecimento.

\section{ANÁlise da RELAÇão ENTRE A APLICAÇÃo dAS REgRAS E A SEGURANÇA JURÍDICA}

Apesar de preencher o centro do direito com uma composição de regras, Hart (2001) não foi ingênuo ao ponto de trazer que regras jurídicas sempre predeterminariam o resultado de uma disputa. Ao falar sobre o ceticismo sobre as regras, expõe justamente as dificuldades que se encontram para que estas desempenhem seu papel dentro do sistema jurídico. Dessa forma, leva a crer que, na verdade, o que realmente existe é uma ilusão de previsibilidade, que é proporcionada pelas regras jurídicas.

[...] a forma de cepticismo que mais tem prevalecido na Inglaterra e nos Estados Unidos convida-nos a reconsiderar o ponto de vista de que um sistema jurídico é constituído totalmente, ou mesmo primariamente, por regras. Não restam dúvidas de que os tribunais proferem os seus julgamentos de forma a dar a impressão de que as suas decisões são a consequência necessária de regras predeterminadas cujo sentido é fixo e claro. Em casos muito simples, tal pode ser assim; mas na larga maioria dos casos que preocupam os tribunais, nem as leis, nem os precedentes em que as regras estão alegadamente contidas admitem apenas um resultado (HART, 2001, p. 16, grifo do autor).

As regras gerais, segundo Hart (2001), mesmo quando formuladas verbalmente, podem dar ensejo às incertezas quanto à sua aplicação em determinados casos particulares. A 
regra nem sempre dirá quando deve incidir sobre alguma situação fática e nem mesmo a lógica chega a tempo de resolver este impasse. Há um limite, proveniente da linguagem, que demarcará o campo ativo de uma regra geral. "Haverá [...] casos simples que estão sempre a ocorrer em contextos semelhantes, aos quais as expressões gerais são claramente aplicáveis [...] mas haverá também casos em que não é claro se se aplicam ou não [...]" (HART, 2001, p. 139).

Os casos simples se disfarçam com uma miragem de clareza proporcionada pelas regras que parecem não necessitar de interpretação (HART, 2001). Contudo, esses casos, que parecem não ser problemáticos, adquirem essa fantasia simplista devido à sua repetida constância em um meio homogêneo, motivo pelo qual repousam sobre um acordo geral sobre os termos contidos nas regras e sua aplicabilidade ao caso concreto. Posner (2007) associa, nesse sentido, a objetividade do direito a um consenso político. Acredita que o raciocínio jurídico será convincente quando houver um consenso sobre os valores políticos e sociais relevantes. Desse modo, critica:

\begin{abstract}
A idéia (sic) de que a interferência política no processo de investigação deve ser evitada é menos problemática do que a idéia (sic) de que a objetividade em direito depende da coincidência de que um consenso político se tenha formado em torno das premissas da análise judicial. O que é consenso político senão um termo polido para a vontade do mais forte? Do mesmo modo, o que são os juízes que proferem sentenças "objetivas" senão pessoas que deduzem as implicações das relações de poder na sociedade? (POSNER, 2007, p. 169).
\end{abstract}

Posner (2007) elenca, dessa forma, o que considera os problemas com a governança por regras. Para ele, a incidência incerta de uma regra pode exigir dos juízes uma contínua ponderação, pois a regra nem sempre poderá apreender a realidade descrita e, na ausência de um complemento legislativo, sua aplicação ou não dependerá de um juízo subjetivo. Para Posner (2007, p. 62), "as decisões que se exige que os juízes tomem para aplicar as regras aos fatos podem ser descritas quer como interpretação, quer como criação de exceções e ajustes ad hoc - na verdade, uma contínua reformulação das regras." Ainda, completa: "quanto mais antiga a regra, e quanto mais dinâmica a atividade regida por ela [...] mais os juízes serão pressionados a criar exceções e expansões ad hoc" (POSNER, 2007, p. 62).

Outro problema citado por Posner (2007) referente à governança por regras está na situação em que duas ou mais regras de diferentes orientações podem incidir sobre o mesmo fato. Não raro, elas podem ser diametralmente opostas e logicamente incompatíveis, ao ponto de novamente o juiz ter de entrar em cena e eliminar a antinomia. A lógica, contudo, não lhe diz qual regra escolher. Da mesma forma, admitindo-se a eficácia estrutural das regras, estas 
ainda poderiam existir em tão grande número que sua assimilação se tornaria completamente inviável e seus benefícios, obsoletos. Assim, as regras acabam por dar ensejo justamente ao fenômeno que, supostamente, haveriam de sanar: a discricionariedade judicial.

O raciocínio pelo qual o magistrado passa, no qual verifica o fato e encontra um perfeito encaixe numa dada regra, é o plano máximo idealizado pelos formalistas em Direito. Bastaria, portanto, encontrar um conceito imutável e universal, que faria com que a certeza atingisse seu mais alto grau de aplicação. $\mathrm{O}$ formalismo, impregnado pelo silogismo, encontra diversas críticas em Posner (2007). O formalista, segundo ele, possui uma alta confiança nas premissas e nos meios de extrair conclusões delas. Para Posner (2007), o operador jurídico formalista, proveniente do positivismo, "está convencido de que o direito consiste apenas nas ordens legislativas, ou em outros comandos oficiais que, cuidadosamente interpretados, produzem resultados demonstravelmente corretos em todos os casos" (p. 54).

Este, porém, é um ideal inatingível. Ignorar o papel subjetivo do juiz na formação de uma decisão judicial é ignorar a própria essência desta. Talvez aqui o cético sobre as regras, mediante a frustração por elas causada, tenha adquirido sua descrença ao verificar que a certeza e a determinabilidade esperadas não são sempre atingidas pelas regras. Estas, segundo Hart (2001), são uma forma de comunicação de padrões de conduta. Contudo, é uma ilusão a premissa de que irão conseguir regular todas as variáveis de absolutamente todos os eventos que porventura venham a ocorrer. Esta situação só seria possível num mundo onde tudo pudesse ser conhecido e todas as possibilidades antevistas. Este mundo, contudo, não pertence aos homens. Há uma zona interpretativa, presente nas regras, chamada pelo autor de textura aberta. Nesta área, o trabalho interpretativo consiste em estabelecer as premissas para a aplicação de uma regra, o que implica numa observação do intérprete que deverá acolher os elementos necessários para melhor atingir a finalidade do dispositivo jurídico. Este exercício, entretanto, não leva ao total comprometimento da segurança jurídica. Pelo contrário, a textura aberta, que é uma característica própria da linguagem, se relaciona com as regras de forma a resguardá-las do perigo de conservar conceitos estagnados que, com o tempo, revelam uma completa dissintonia entre o texto legal e a realidade descrita.

Portanto, o fato de que existe uma margem à interpretação em toda aplicação de uma regra não implica dizer que se perderá a segurança jurídica. Na verdade, se considerada a textura aberta como uma característica essencial e relativamente positiva das normas, devido à própria natureza da linguagem, a segurança jurídica, neste aspecto, só será inviável ou mesmo mitológica se esperada uma resolução pronta e objetiva dos conflitos jurídicos pelo teor das regras estabelecidas. 


\section{AS REGRAS JURÍDICAS ATRAVÉS DA SEMÂNTICA: UMA ANÁLISE EXEMPLIFICATIVA DA ADI 4277 DO STF}

Hart (2001), como se viu, chamou de textura aberta do Direito a característica resultante da indeterminabilidade gerada pela comunicação dos padrões de comportamento. Como visto, mesmo as regras, como veículos de transmissão destes padrões, deixam uma margem de discricionariedade para a atuação do intérprete. Na verdade, o próprio autor parece indicar que o cerne da questão da objetividade e da determinabilidade desejadas para as regras jurídicas está ligada a uma investigação mais profunda, diretamente ligada a questões de linguagem.

Considerando o Direito positivo de um país como enunciações que compõem um corpo linguístico, partir-se-á, então, para a investigação das regras como unidades operacionais a partir de seus elementos estruturais linguísticos. A semiótica, neste contexto, é uma face do estudo da linguagem que analisa o signo a partir de sua realidade bifásica, que, para Carnap segundo Warat (1995), compõe-se de elementos chamados indicador e indicado. O indicador veicula-se num plano material, através do som, da grafia ou do gesto, enquanto que o indicado constitui-se como o fenômeno ou situação do mundo comunicado por meio do indicador. Conforme Warat (1995),

\footnotetext{
O signo, assim caracterizado, pode ser estudado sob três pontos de vista, atendendo ao fato de que pode ser considerado como elemento que mantém três tipos de vinculações: com os outros signos; com os objetos que designa; com os homens que o usam. A primeira vinculação é chamada sintaxe; a segunda, semântica; a terceira, pragmática. Estes três níveis de análise constituem as partes da semiótica, entendida como a teoria geral de todos os signos e sistemas de comunicação. (p. 39, grifo do autor)
}

Pensa-se, então, no signo e sua característica bifásica promovida por meio de processos implícitos, nos quais os indivíduos convencionam sobre o funcionamento da relação indicador/indicado. Conforme Warat (1995, p. 27), “[...] a convenção é quase que absoluta em sistemas como os sinais de trânsito, mas com uma forte graduação de convencionalidade nos códigos de cortesia ou em uma retórica estereotipada [...]".

Quando é trazida esta concepção para o Direito, percebe-se um declínio ainda maior do grau de convenção dos indivíduos, tornando o valor do signo variável conforme o usuário. As convenções vagas e abertas acabam tornando-se, por consequência, muito mais impregnadas de dimensões ideológicas dos significados do que aquelas em que existe unanimidade. Tal proposição lembra a fala de Posner (2007) referida anteriormente, quando 
este tratava da associação de um consenso político à objetividade do raciocínio jurídico. Aqui, far-se-á uma breve ilustração das propostas trazidas à tona por Warat (1995) através da análise do conteúdo da ADI 4.277.

A Ação Direta de Inconstitucionalidade no 4.277 versa sobre a constitucionalidade da união estável homoafetiva, face à regra contida no art. 1.723, do Código Civil Brasileiro, transcrita in verbis: "É reconhecida como entidade familiar a união estável entre o homem e a mulher, configurada na convivência pública, contínua e duradoura e estabelecida com o objetivo de constituição de família" (BRASIL, 2002).

A regra, prima facie, não parece dar ensejo a alguma forma de dúvida quanto à sua aplicação se vista de forma isolada no sistema. Os primeiros questionamentos que a envolvem surgem de seu impacto com o princípio da igualdade, sacramentado pelo Texto Constitucional. Dessa forma, primeiramente o relator põe em evidência o silêncio constitucional sobre o correto emprego do aparelho sexual humano (STF, 2011). Da mesma forma, lembra que, segundo o art. 5 , II, da referida Carta Magna, o constituinte optou por positivar a regra de clausura ou fechamento hermético do Direito (STF, 2011). Isto se deu, nas palavras do relator, "[...] pois o silêncio normativo, aqui, atua como absoluto respeito a algo que, nos animais em geral e nos seres humanos em particular, se define como instintivo ou da própria natureza das coisas" (STF, 2011, p. 16). Com este pensamento, enlaça a ideia de instinto com os conceitos de preferência e orientação, de forma que sexualidade humana abranja tanto esses conceitos como o aparelho genital humano. Dessa maneira, veda-se a discriminação pela orientação sexual por ela fazer parte indissolúvel da sexualidade humana (STF, 2011). Assim, o relator demonstra que

\footnotetext{
o reconhecimento jurídico da homoafetividade passa pelo crivo do princípio da dignidade da pessoa humana, na medida que "se as pessoas de preferência heterossexual só podem se realizar ou ser felizes heterossexualmente, as de preferência homossexual seguem na mesma toada: só podem se realizar ou ser felizes homossexualmente (STF, 2011, p. 20).
}

Reconhecido constitucionalmente o fenômeno da homoafetividade pelo Ministro Relator, a questão restante estava relacionada à possibilidade de os casais homoafetivos serem destinatários do mesmo regime jurídico-protetivo destinado a casais heteroafetivos "em situação de voluntário enlace igualmente caracterizado pela estabilidade” (STF, 2011, p. 29).

Neste momento, quando o enfoque do voto do relator passa para o caput do art. 226, da Carta Magna, no qual a família, base da sociedade, tem especial proteção do Estado, vislumbrase a presença da textura aberta trazida por Hart (2001), pois o questionamento na decisão 
voltou-se para a tarefa de estabelecer o significado da palavra família, a fim de poder se resolver a questão da aplicabilidade do art. 1.723 do CCB às uniões homoafetivas. O problema não reside na clareza da regra, mas na dificuldade que se encontra em identificar as premissas para que ela possa ser aplicada. Logo, um conceito estático de família, que estivesse presente no ordenamento jurídico, longe de ser solução, iria tornar a regra ultrapassada por não poder acompanhar as transformações sociais que envolvem um conceito tão dinâmico. O problema está na definição linguística do que será considerado ou não família, de forma a pensar que seria ingênuo considerar a inexistência de esforço interpretativo no estabelecimento das premissas antes mesmo da aplicação das regras.

Com isto, volta-se para o estudo do signo, desta vez para o que Warat trouxe como semântica. A semântica, segundo Warat (1995, p. 40), "estuda os signos em suas relações com os objetos a que se referem". Na ADI 4.277, a questão semântica consistia centralmente na dúvida sobre a qual objeto se refere o signo verbal família. Por certo que, como Hart (2001) outrora havia constatado com o conceito de regra e de Direito, torna-se fácil encontrar exemplos para o termo família, mas um exercício exaustivo procurar uma definição para este. Neste caso, a dificuldade talvez exista devido a radicais mutações que o signo sofreu durante os últimos dois séculos. Num estudo sobre a semiologia de Saussure, Warat (1995) diz que:

\footnotetext{
Em suma, a mutabilidade do signo indica a necessária possibilidade do desvio da relação significante/significado. Esta evolução, segundo Saussure, é inevitável, pois não há exemplo de língua que tenha resistido a tal princípio, uma vez que ao fim de certo tempo sempre é possível a verificação de desvios sensíveis (p. 27).
}

Nestes termos, é inviável pensar que o modelo patriarcal de família, embora subsistente, seja o único modelo associado ao indicador do signo família. Fatores como o movimento feminista, por exemplo, não raro inverteram a concepção até então construída patriarcalmente. Com isso, percebe-se que os elementos sociais e temporais no mínimo instigam a mutação sígnica. Warat (1995) faz a seguinte observação:

Com respeito à mutabilidade do signo jurídico, deve-se indicar que o caráter histórico e social a ele atribuído quando falamos de sua imutabilidade, nos obriga a verificar que as forças sociais, em sua dinâmica, submetem à incessante mudança todos os processos de significação (p. 28).

$\mathrm{Na}$ decisão da ADI, o relator já adianta seu ponto de vista ao anunciar estender o campo denotativo de família para além de um fato biológico, mas também cultural e espiritual (STF, 2011). Da mesma forma, desvincula sua formação de atos cartorários ou de liturgias 
religiosas. Considera família a "mais natural das coletividades humanas", sendo seu cerne um ambiente preenchido com afetividade, emparceiramento e admiração ético-espiritual, no qual há uma busca pela felicidade, distendida no tempo e à vista de todos (STF, 2011, p. 33). Dessa forma, foge de uma significação ortodoxa e formal, restrita às uniões heteroafetivas. Existe, dessa maneira, uma notória e constante preocupação em estabelecer tal posicionamento como verdade a respeito de família, de forma a tornar válida e coerente a decisão proferida. Warat (1995), nesse aspecto, justifica esta atitude ao afirmar que o problema central da semântica é o problema da verdade. A insistência do relator em encontrar um significado para família indica uma tentativa de pacificação semântica, pois, segundo Warat (1995),

Uma expressão lingüística (sic), bem formulada sintaticamente, é semanticamente verdadeira se pode ser empregada para subministrar uma informação verificável sobre o mundo, ou seja, se tem correspondência com os fatos, se sua situação significada é aceita como existente (p. 40).

Assim, firmado o campo semântico, o Ministro pode direcionar sua decisão a ponto de dar uma nova interpretação para o art. 1.723, do CCB, e afirmar constitucional a união estável homoafetiva. Tal decisão serve como exemplo para mostrar a deficiência objetiva de uma regra aparentemente clara, assim como evidenciar como uma decisão julgada pelo Supremo Tribunal Federal pode girar em torno de questões semânticas/linguísticas. Ampliase, desta maneira, o paradigma vigente na resolução dos problemas em Direito, de forma a abraçar ferramentas, técnicas e estudos da linguística para alcançar resultados de conflitos jurídicos.

\section{CONSIDERAÇÕES FINAIS}

Não é a intenção, de forma alguma, encerrar a discussão da aplicabilidade das regras jurídicas, vistas como um problema da semântica, na curta dimensão deste trabalho. A preocupação em compreender o Direito através de suas correntes tem gerado debates extremos entre renomados cientistas jurídicos. O direito, como fenômeno social, transformase conforme a sociedade o faz. Portanto, diante desta incessante metamorfose, aqui apenas lança-se luz para a compreensão de uma parcela do Direito, que são suas regras jurídicas. 
Com o curto espaço deste trabalho, pretendeu-se mostrar que, apesar das especificidades das regras, estas não falarão por si mesmas em diversos casos, tornando, o que antes parecia cristalino, em uma zona obscura e tempestiva.

A objetividade das regras, entretanto, já é pauta de uma discussão cheia de farpas e espinhos, sendo alvo de críticas, principalmente pelos seus céticos. A questão semântica, neste ponto, insere uma perspectiva diferente para ser visualizada esta problemática. Pensa-se na semântica como uma semente de solução para se visualizar a crise interpretativa, para que, talvez a pragmática, mais a frente, traga um ângulo que anuncie uma nova forma de lidar com os signos jurídicos.

Dessa forma, lança-se a proposta de estudar os conflitos jurídicos através dos utensílios proporcionados pela linguística. Assim, renova-se o paradigma de pesquisa e compreensão do Direito, fazendo-o multidisciplinar, de maneira a que possa englobar maiores soluções e explicações para o dinâmico fenômeno jurídico.

\section{REFERÊNCIAS}

BARZOTTO, L. F. O positivismo jurídico contemporâneo: uma introdução a Kelsen, Ross e Hart. 2 ed. Porto Alegre: Livraria do Advogado, 2007.

BRASIL. Constituição (1988). Constituição da República Federativa do Brasil. Brasília, DF, Senado, 1998.

BRASIL. Lei nº 10.406, de 10 de janeiro de 2002. Código Civil. Brasilía, DF, Senado, 2002.

BRASIL. Supremo Tribunal Federal. Ação direta de inconstitucionalidade $n^{o} 4.277$. Voto do Ministro Ayres Britto. Julgado em 05.05.2011. Disponível em:

<http://www.stf.jus.br/arquivo/cms/noticiaNoticiaStf/anexo/ADI4277revisado.pdf >. Acesso em: 16 de jun. de 2014.

HART, H. L. A. O conceito de direito. Lisboa: Fundação Calouste Gulbenkian, 2001.

MACCORMICK, N. H. L. A. Hart. In: O conceito de direito de Hart. São Paulo: Elsevier, 2007.

POSNER, R. A. A Problemática da teoria moral e jurídica. São Paulo: Martins Fontes, 2012. Problemas de filosofia do direito. São Paulo: Martins Fontes, 2007.

WARAT, L. A. O direito e sua linguagem. 2 ed. Porto Alegre: Sergio Antonio Fabris Editor, 1995. 